\title{
Embryotoxicity and fetotoxicity following intraperitoneal administrations of hexavalent chromium to pregnant rats
}

\author{
Neila Marouani ${ }^{2}$, Olfa Tebourbi ${ }^{2}$, Moncef Mokni ${ }^{2}$, Mohamed Tahar Yacoubi ${ }^{3}$, Mohsen Sakly ${ }^{2}$, \\ Moncef Benkhalifa ${ }^{4}$ and Khémais Ben Rhouma ${ }^{2}$ \\ Laboratoire de Physiologie Intégrée, Faculté des Sciences de Bizerte, Jarzouna, Tunisia; Service d'Anatomie et de Cytologie \\ Pathologiques, Hôpital Universitaire Farhat Hached, Sousse, Tunisia; and ATL R\&D, Reproductive Biology and Genetics \\ Laboratory, Paris La Verrière, France and Unilabs Group Geneva, Switzerland
}

Date submitted: 25.09.09. Date accepted: 22.03.10

\section{Summary}

\begin{abstract}
Heavy metals are omnipresent in the environment, and industrial use has greatly increased their presence in soil, water and air. Their inevitable transfer to the human food chain remains an important environmental issue as many heavy metals cause a range of toxic effects, including developmental toxicity. Administration of chromium VI ( 1 and $2 \mathrm{mg} / \mathrm{kg}$ as potassium dichromate) through intraperitoneal (i.p.) injection during organogenesis (days 6 to 15 of gestation) in rats revealed embryo- and fetotoxic effects. Reduced fetal weight, retarded fetal development, number of fetuses per mother and high incidences of dead fetuses and resorptions in treated mothers were also observed. Gross morphological abnormalities, such as displayed form of edema, facial defect, lack of tail, hypotrophy, severs subdermal haemorrhage patches and hypotrophy of placenta were observed in fetuses after chromium VI-treated mothers. A skeletal development of fetuses presented an incomplete ossification in nasal, cranium, abdominal or caudal bones in rats treated with $1 \mathrm{mg} / \mathrm{kg}$ of chromium, whereas rats treated with $2 \mathrm{mg} / \mathrm{kg}$ showed ossification and absence of the sacral vertebrae compared with the control. At a higher dose of chromium, histological changes were found in fetuses with atrophy of theirs vital organs. Placental histological observations revealed a pronounced morphological alteration, with atrophy of decidual cells, a degenerated of chorionic villi and hypertrophy of blood lacuna. The present study suggests a risk to the developing embryo when the mother is exposed to a high concentration of chromium VI during organogenesis.
\end{abstract}

Keywords: Embryotoxicity, Hexavalent chromium, Malformations, Placenta, Skeletal

\section{Introduction}

One example of heavy metals is chromium, which is a naturally occurring element found in rocks, plants, animals, volcanic soils dust and gases (Nriagu et al., 1988). Chromium is extensively used in metallurgical processes, such as chrome plating, pigment production, tanning, textile, ceramic, glass and photographic industries. Chromium occurs in

\footnotetext{
${ }^{1}$ All correspondence to: khemais.benrhouma@fsb.rnu.tn

${ }^{2}$ Laboratoire de Physiologie Intégrée, Faculté des Sciences de Bizerte, 7021 Jarzouna. Tunisia.

${ }^{3}$ Service d'Anatomie et de Cytologie Pathologiques, Hôpital Universitaire Farhat Hached, 4000 Sousse. Tunisia.

${ }^{4}$ ATL R\&D. Reproductive Biology and Genetics Laboratory. Paris La Verrière, France and Unilabs Group Geneva.
}

the workplace predominantly in two valency states: hexavalent chromium (chromium VI) and trivalent chromium (chromium III). The hexavalent form is usually linked with oxygen and is a strong oxidizing agent. It is widely known to cause allergic dermatitis, as well as toxic and carcinogenic effects in humans and animals (Norseth, 1981; Von Burg et al., 1993; Domingo, 1994; Stohs et al., 1995, Kawanishi et al., 2002). High levels of chromium are reported to impair gestational development as evidenced by epidemiological studies in female workers exposed to this metal in the work environment (Shmitova, 1978, 1980). Exposure to chromium VI can induce complications during pregnancy and child birth (Shmitova, 1978, 1980). It was reported that chromium VI induces developmental effects include post-implantation losses, resorptions, reduced fetal weight and malformations including 
reduced ossification (E.P.A., 1998; Wilbur et al., 2000; European Commission, 2005). A previous study (Pribluda, 1963) reported the transfer of chromium from the mother to the fetus bones in human. Pribluda (1963) demonstrated that the chromium content of bones of pregnant rats decreases with advancing gestation. Such released chromium may reach the circulatory system and enter feto-placental tissues through the placental barrier. However, the toxic effects of chromium VI on embryo-fetal development in rats are still unclear. The present study was carried out to determine the effect of chromium VI given through intraperitoneal injection during the period of organogenesis during embryogenesis and fetal development, as well as its effects on various regions of fetuses bone. Moreover, the morphology and the histology of placenta and fetuses were investigated.

\section{Materials and methods}

\section{Animals and reagents}

Two-month-old Wistar female rats (150 g) were used in this study. Rats were housed under controlled conditions of temperature $\left(22 \pm 1{ }^{\circ} \mathrm{C}\right)$, with a 14 -h light/dark cycle. Female rats of proven fertility were kept for mating (2:1) with normal healthy adult males overnight. The day at which sperms were found in the vaginal smear was designated as day 0 of gestation. These pregnant females were divided into three equal groups $(n=8)$ of approximately similar weight as follows: (1) animals received an intraperitoneal injection (i.p.) of potassium dichromate $\left[\left(\mathrm{K}_{2} \mathrm{Cr}_{2} \mathrm{O}_{7}\right)\right.$ purchased from Hopkin and Williams Searle Co., London, England] diluted with $\mathrm{NaCl}$ solution 9\% at dose of $1 \mathrm{mg} / \mathrm{kg}$ body weight (b.wt); (2) animals were administered $2 \mathrm{mg}$ of potassium dichromate $/ \mathrm{kg}$ b.wt; and (3) the control group received equal volumes of vehicle, from days 6 to 15 of gestation. The animals were kept in polycarbonate cages individually and were given feed and water ad libitum. The dams were observed daily for change in body weight and physical signs of toxicity, if any. After 19 days of gestation, all animals were killed by decapitation; the number of fetuses/litter, number of live/dead fetuses, crown-rump length, number of resorptions, number of implantations, weight of uteri, of fetuses and their respective placenta were recorded. Post-implantation loss was calculated on the basis of previous report (Lee et al., 2009):

$$
\begin{aligned}
& \text { post-implantation } \\
& =[\text { (total implantations }- \text { live fetuses }) / \\
& \quad \text { total implantations }] \times 100 .
\end{aligned}
$$

\section{Morphological evaluation of the offspring}

The left and the right uterine horns were removed and the rat was terminated. The first implantation site next to the ovary was denoted following the convention position 1 in order to the last position in the uterine horn next to the cervix. Each embryo, from right and left uterine horn regarding to intrauterine position, was removed to examine the gross malformations. Structural deviations from normal development were considered as denoted malformations, i.e. facial defects, body malrotation and neural tube defects. Malformed and non-malformed offspring were subsequently examined for skeletal anomalies. A skeletal radiographic (General Electric; voltage $27 \mathrm{kV}$, intensity $5 \mathrm{~mA}$ ) was done to observe the effect of chromium VI on various regions of bone (nasal bone, cranium, abdominal, caudal) in fetuses.

\section{Histological analysis}

Placenta and fetuses were fixed overnight at room temperature by direct immersion in $4 \%$ paraformaldehyde in $0.1 \mathrm{M}$ phosphate buffer, $\mathrm{pH}$ 7.4. The samples were dehydrated with an ethanol and toluene series and embedded in paraffin. Serial sections $(4 \mu \mathrm{m})$ were mounted on gelatin-coated glass slides cut and stained with haematoxylin and eosin.

\section{Statistical analysis}

Data were analysed using Stat View $512^{+}$software (Abacus Concept). The results were expressed as means $\pm \mathrm{SE}$ and a comparison of two means was made using Student's $t$-test.

\section{Results}

No notable changes in behaviour or clinical signs were observed in the control or in the treated dams. No mortality was observed during the experimental period. The dams treated with 1 and $2 \mathrm{mg}$ of chromium/ $\mathrm{kg}$ b.wt day-1 presented a significant reduction in body weight gain during treatment period (Table 1). This decrease was about $29 \%$ and $60 \%$ compared with the control group. The relative weight of uterus was also decreased after i.p. injection of chromium during the organogenesis period, this decrease reached $21 \%$ and $30 \%$ of controls for 1 and $2 \mathrm{mg}$ of chromium $/ \mathrm{kg}$ b.wt day-1, respectively. The number of fetuses/ litter was significantly reduced in treated groups when compared with controls $(6.43 \pm 0.75$ and $6.29 \pm 1.13$ respectively with 1 and $2 \mathrm{mg}$ of chromium $/ \mathrm{kg}$ b.wt versus $9.75 \pm 0.37$ ). Fetal weight and crown rump 
Table 1 Chromium-induced embryotoxicity and fetotoxicity in rats treated during organogenesis

\begin{tabular}{lllr}
\hline & & \multicolumn{2}{c}{ Chromium } \\
\cline { 3 - 4 } & Control & $1 \mathrm{mg} / \mathrm{kg}$ & $2 \mathrm{mg} / \mathrm{kg}$ \\
\hline Weight gain in mother (g) & $83 \pm 2.45$ & $58.8 \pm 1.81^{b}$ & $33 \pm 11.48^{b}$ \\
Relative weight of uterus (g/100g) & $2.03 \pm 0.02$ & $1.60 \pm 0.20^{a}$ & $1.42 \pm 0.22^{a}$ \\
No. of fetuses (dead and live)/ litter & $9.75 \pm 0.37$ & $6.43 \pm 0.75^{b}$ & $6.29 \pm 1.13^{b}$ \\
No. of dead fetuses (no. of litters) & All live & $2(2)$ & $7(4)$ \\
Fetal weight (g) & $3.86 \pm 0.04$ & $3.06 \pm 0.13^{a}$ & $2.61 \pm 0.15^{b}$ \\
Placental weight (g) & $0.58 \pm 0.006$ & $0.52 \pm 0.01^{a}$ & $0.41 \pm 0.01^{b}$ \\
Crown rump length (cm) & $3.71 \pm 0.05$ & $2.92 \pm 0.08^{a}$ & $2.76 \pm 0.08^{b}$ \\
No. of resorption sites & $0.13 \pm 0.12$ & $0.29 \pm 0.28$ & $0.42 \pm 0.20^{a}$ \\
No. of implantations & $9.88 \pm 0.30$ & $6.72 \pm 0.57^{a}$ & $6.71 \pm 1.04^{a}$ \\
Post implantation loss (\%) & $1.39 \pm 1.38$ & $9.08 \pm 5.56^{a}$ & $23.92 \pm 6.52^{b}$ \\
\hline
\end{tabular}

Values represent mean \pm standard error (SE) of 8 rats in each group. Chromium treatment was preformed as described in the Methods section.

${ }^{a} p<0.05$ compared with controls (Student's $t$-test).

${ }^{b} p<0.001$ compared with controls (Student's $t$-test).

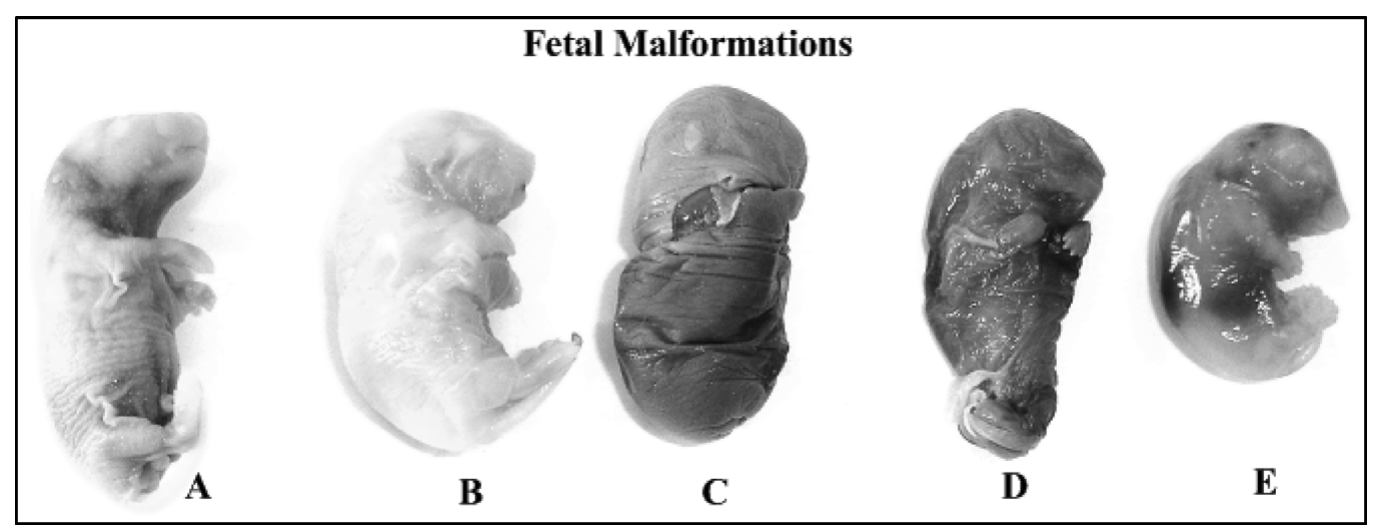

Figure 1 Type of malformations in fetuses of pregnant rats in 19 days of gestation. Rats received an i.p. injection of $2 \mathrm{mg} / \mathrm{kg}$ body weight of potassium dichromate during the organogenesis period. $(A)$ Normal; $(B, C)$ edema; $(C, D)$ facial defect, lack of tail and severe subdermal haemorrhage patches; $(E)$ hypotrophy and presence of haemorrhage areas (arrowed).

length were also significantly decreased in groups treated with chromium. This decrease was about $20.7 \%$ and $32.4 \%$ in fetal weight and $21.3 \%$ and $25.6 \%$ in crown rump length respectively in rats treated with 1 and $2 \mathrm{mg}$ of chromium $/ \mathrm{kg}$ compared with the control. Our data indicate that the placenta weight was significantly reduced in groups treated with chromium $(0.52 \pm 0.01$ and $0.41 \pm 0.01$ respectively with 1 and $2 \mathrm{mg}$ of chromium $/ \mathrm{kg}$ b.wt versus $0.58 \pm$ 0.006). The incidences of dead fetuses were high in groups treated with chromium compared with the control group. The number of resorption sites was found to be dose dependent. The higher dose caused more incidences of resorption sites than the lower one $(0.29 \pm 0.28$ and $0.42 \pm 0.20$ respectively with 1 and $2 \mathrm{mg}$ of chromium $/ \mathrm{kg}$ b.wt versus $0.13 \pm 0.12$ ). The i.p. injection of chromium during the organogenesis period decreases significantly the number of implantations. This decrease was about
$31.9 \%$ and $32 \%$ respectively in rats treated with 1 and $2 \mathrm{mg}$ of chromium $/ \mathrm{kg}$ compared with the control. Controversy, the data revealed significantly higher incidences of post implantation loss in treated groups (9\% and 24\%, respectively with 1 and $2 \mathrm{mg}$ of chromium/kg b.wt) (Table 1).

Gross structural abnormalities in the form of edema and subdermal haemorrhagic patches were observed on the thoracic and abdominal regions in fetuses of pregnant rats treated with $1 \mathrm{mg}$ of chromium $/ \mathrm{kg}$ when compared with controls (data not shown). The changes were more significant in groups treated with a high dose of chromium (2 mg/ $\mathrm{kg}$ ) compared with the preceding lower-dose group. Morphological study of the fetuses, from treated rats with $2 \mathrm{mg}$ of chromium $/ \mathrm{kg}$, showed gross malformations like edema, facial defect, lack of tail, hypotrophy and severe subdermal haemorrhage patches compared with the control (Fig. 1). 


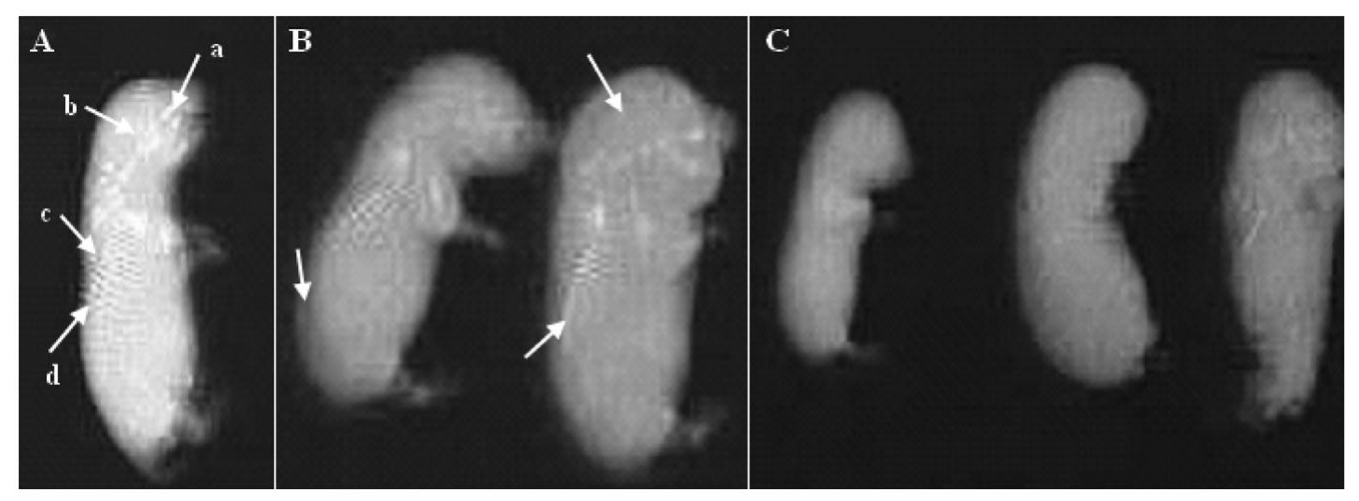

Figure 2 Title: A skeletal radiographic of fetuses from control $(A)$ and chromium-treated rats with $1 \mathrm{mg} / \mathrm{kg}(B)$ and $2 \mathrm{mg} / \mathrm{kg}$ (C) during the organogenesis period. $(A)$ Fetuses showed the presence of four sacral vertebrae (a: nasal bones, b: cranium bones, c: abdominal bones, d: caudal bones). (B) Fetuses showed incomplete ossification (arrowed). (C) Fetuses showed the absence of any vertebrae.
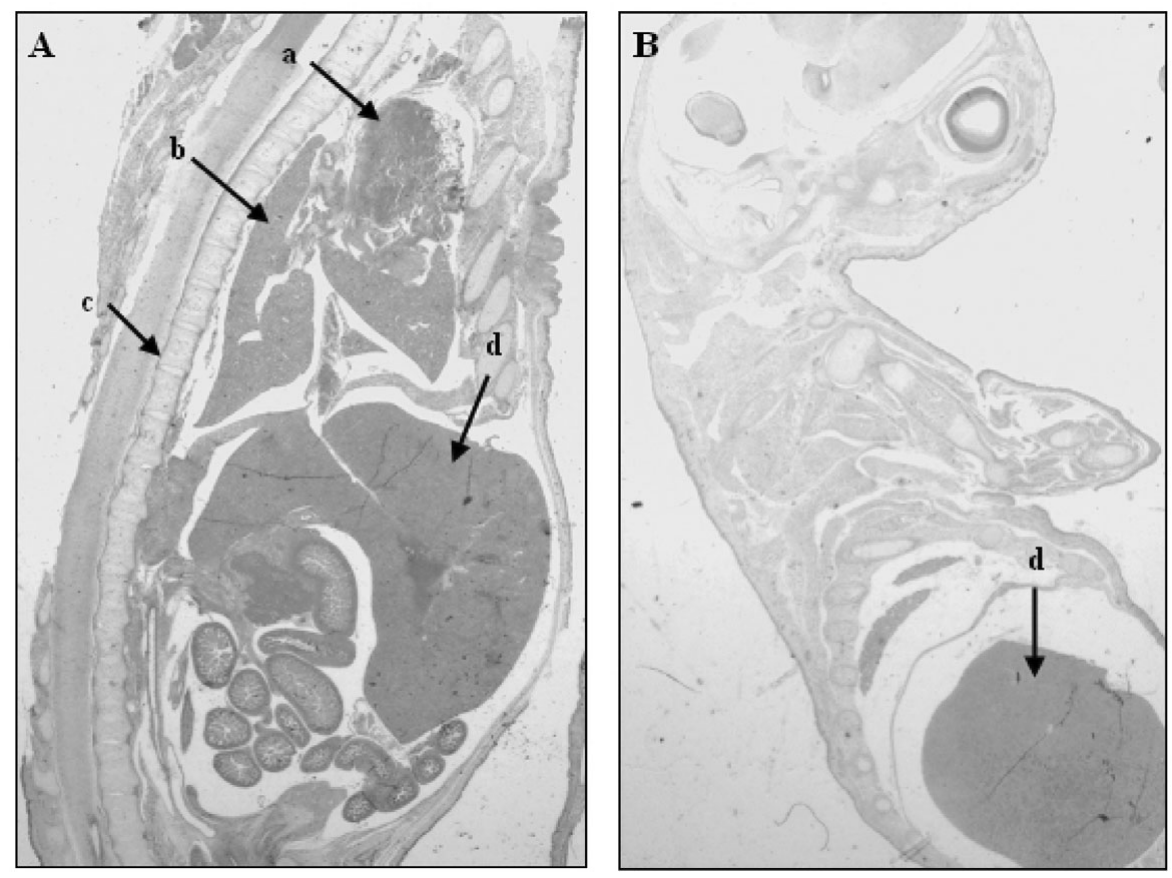

Figure 3 Photomicrographs of sections of fetuses from control $(A)$ and chromium-treated rats with $2 \mathrm{mg} / \mathrm{kg}(B) \mathrm{during}$ the organogenesis period. Fetuses were fixed by direct immersion in paraformaldehyde solution. Serial $(5 \mu \mathrm{m})$ sections were mounted on gelatin coated glass slides and stained with hematoxylin and eosin. (a) Heart; (b) lung; (c) sacral vertebrae; (d) liver.

A skeletal development of fetuses, presented in Fig. 2, showed dose-related effects. In the $1 \mathrm{mg} / \mathrm{kg}$ treated group, fetuses presented only an incomplete ossification in nasal, cranium, abdominal or caudal bones compared with the control. Whereas, the most striking abnormality seen in X-rays was absence of ossification of the sacral vertebrae: this situation occurred in the fetuses from the pregnant rats injected with $2 \mathrm{mg}$ of chromium $/ \mathrm{kg}$ during the organogenesis period. Light microscopic inspection of fetuses from rats treated with a high dose of chromium revealed an atrophy of organs such as liver, lung, heart and skeletal compared with the control (Fig. 3). Placentas from dams given $\mathrm{K}_{2} \mathrm{Cr}_{2} \mathrm{O}_{7}$ during the organogenesis period showed some morphological alterations when compared with the control group (Fig. 4). The placentas exhibited dose-dependant hypotrophy macroscopically in rats injected with chromium 1 and $2 \mathrm{mg} / \mathrm{kg}$. Histopathologically, in the treated group, increased dose-dependant thickness was noted significantly in the decidua basalis with atrophy of decidual cells. Furthermore, we observed 

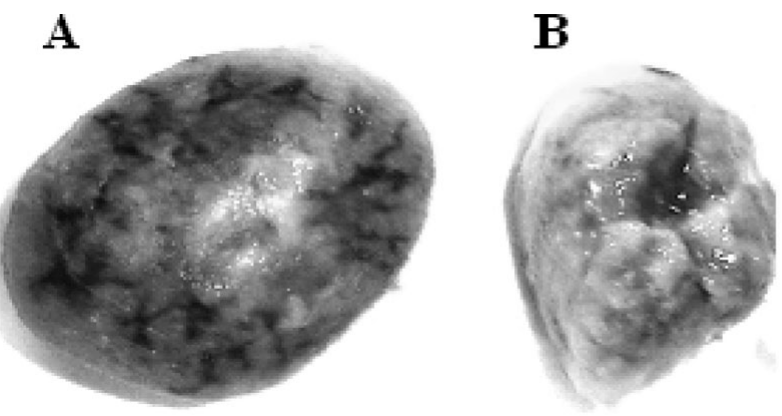

C

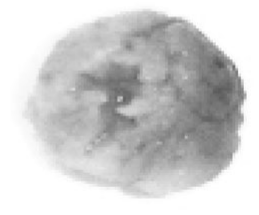

Figure 4 Gross appearance of the placenta of the control $(A)$ and chromium-treated group with $1 \mathrm{mg} / \mathrm{kg}(B)$ and $2 \mathrm{mg} / \mathrm{kg}$ (C). Rats received an i.p. injection of 1 and $2 \mathrm{mg} / \mathrm{kg}$ body weight of potassium dichromate during organogenesis period. $(B, C)$ Marked hypotrophy in the chromium-treated placenta.

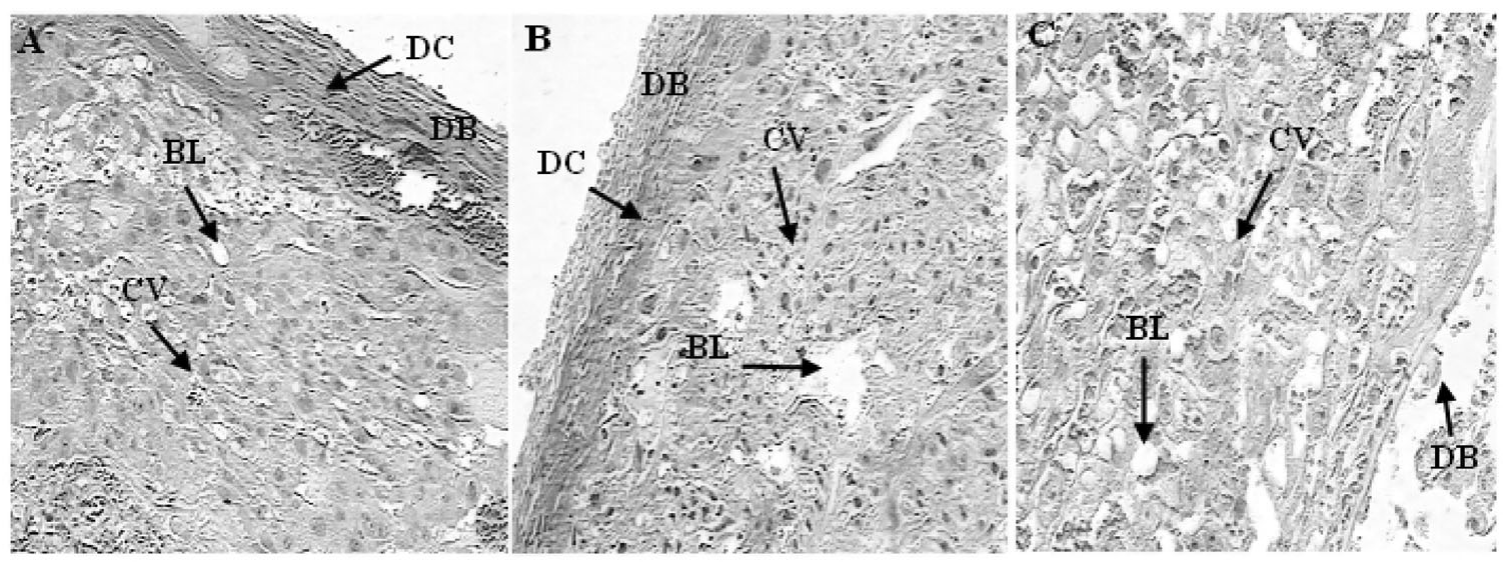

Figure 5 Photomicrographs of sections of placenta from control $(A)$ and chromium-treated rats with $1 \mathrm{mg} / \mathrm{kg}(B)$ and $2 \mathrm{mg} / \mathrm{kg}$ (C) during the organogenesis period. Placentas were fixed by direct immersion in paraformaldehyde solution. Serial $(5 \mu \mathrm{m})$ sections were mounted on gelatin-coated glass slides and stained with hematoxylin and eosin. DB, decidua basalis; DC, decidual cells; BL, blood lacunas; CV, chorionic villi. Magnification: $\times 200(A-C)$.

degeneration of chorionic villi and hypertrophy of blood lacuna that was particularly remarkable in groups treated with a high dose (Fig. 5).

\section{Discussion}

Chromium VI is generally considered to be a carcinogen and mutagen because of its ability to be transported into cells (via oxyanion transporters). Chromium VI is teratogenic and acts without an intermediate (E.P.A., 1998; Wilbur et al., 2000; European Commission, 2005). Moreover, chromium VI is known to be also teratogenic in mice (E.P.A., 1998; Schardein, 2000; Wilbur et al., 2000; European Commission, 2005), which should exclude possible problems of species variation in the embryonic cell test (EST), which is based on murine cell lines. On the other hand, chromium III and chromium VI are considered not to be embryotoxic, but other chromium hexavalent compounds are considered to have similar toxicity effects in humans (Wilbur et al., 2000).

In the present study, chromium VI i.p. injection revealed fetal development retardation and embryo fetotoxicity as evidenced by the reduction in fetal weight, crown rump length, number of fetuses per dam, number of implantations and higher incidences of resorptions sites, embryonic death and post-implantation loss in animals treated with 1 and $2 \mathrm{mg} / \mathrm{kg}$ of chromium. Furthermore, our results indicated that the treatment of pregnant rats with chromium induced a decrease in weight gain in mother and in their uterus's relative weight. Our findings were in accordance with other studies carried out in pregnant rats and have demonstrated that the administration of chromium VI via drinking water causes fetotoxic effects with significant reduction of implantation rate, number of fetuses and an increase in the resorptions number, preimplantation and postimplantation loss for mothers treated with chromium (Junaid et al., 1996a; Kanojia et al., 1996, 1998). 
The decrease in maternal and fetus weight gain during exposure to chromium may be attributed to alteration of maternal physiology because of high blood chromium levels (Kanojia et al., 1998). On the other hand, poor nutrition in pregnant rats leads to intra-uterine growth retardation, post-natal growth failure, changes in the endocrine parameters of the somatotrophic axis, and to increased blood pressure in later life (Woodall et al., 1996; Gluckman et al., 1997; Battista et al., 2002). The relationship between maternal and developmental toxicity is important in making regulatory decisions regarding the developmental toxicity of a chemical.

Accordingly, a systematic and critical approach is needed to characterize the role of maternal toxicity in laboratory animal studies with adverse developmental outcome (Iyer et al., 1999).

The decrease in maternal weight gain during pregnancy clearly indicated that chromium VI was maternally toxic. A possible explanation might be the chromium induced inhibition of cell growth by specific blocking of the progression of cells through the Sphase of the cell cycle (Xu et al., 1996). Previous study (Kanojia et al., 1996) reported that the development of the embryo during gestation was impaired when chromium was administered for 20 days prior to gestation. Gale (1982) injected $8 \mathrm{mg}$ chromium trioxide per $\mathrm{kg}$ intravenously in hamsters on day 8 of gestation and found increased incidence of cleft palate.

The present study showed clearly that chromium exposure through i.p. injection to pregnant rats during the period of organogenesis revealed marked teratological changes in treated fetuses.

The malformed offspring in the uterine harms of treated animals displayed a form of edema, facial defect, lack of tail, hypotrophy and severe subdermal haemorrhage patches compared with the control. Histopathologically, the malformed fetuses showed an atrophy of vital organs such as liver, lung and heart compared with the control. These findings could be explained by the reduction in the uterine vascularization, which induced less blood flow to the implantation sites, consequently inducing fetalplacental growth retardation (Garris, 1984). It was reported that acute interruption of blood flow to the uterine horn was shown to be teratogenic in the rat embryo on gestational days 8-10 (Franklin et al., 1960). On the other hand, studies reported that interrupted uterine blood flow caused growth retardation and fetal mortality, but not somatic malformations (New et al., 1977; Garris, 1984).

Even more interesting, at these stages when the skeleton could be observed, was the presence of many abnormalities with incomplete or absent ossification of sacral vertebrae, which demonstrated that chromium is responsible for the observed vertebral anomalies.
Our results were in accordance with other studies carried out in pregnant mice and have demonstrated that the administration of chromium picolinate, from gestation days 6 to 17, causes a significant increase of the incidence of bifurcated cervical arches in fetuses from treated groups (Bailey et al., 2006). Sankaramanivel et al. (2006) revealed that treatment of rats with chromium i.p. $(0.5 \mathrm{mg} / \mathrm{kg})$, in the form of potassium dichromate for 5 days, provoked an accumulation of chromium 5.2-fold in the vertebrae, 8.9-fold in the femur and 8.7-fold in the calvaria, when compared with control. In vertebrae and calvaria these authors also demonstrated that chromium administration reduced enzymatic activities significantly e.g. alkaline phosphatase (ALP) and tartrate-resistant acid phosphatase (TRAP) and significantly increased calcium concentration, altered bone formation rate and bone morphology in the femur. However, fetal growth is greatly associated with placental development. The placenta is a highly specialized tissue supported by several cell systems involved in both its structure and function in fetal-maternal exchange that suggests a role in regulation of fetal growth during pregnancy. In the present study, we observed that chromium VI caused histological alterations in placenta, such as thickness of decidua basalis, atrophy of decidual cells, a degeneration of chorionic villi and hypertrophy of blood lacuna. Therefore, the retention of chromium in placenta in the treated group have impaired placental physiology resulting in embryo and fetotoxic effects as evidenced by various heavy metals $(\mathrm{Hg}$, Cd) and other xenobiotics (Miller). Chromium VI is more easily transferred to the embryo and fetus (Tipton, 1960; Danielsson et al., 1982). It was reported that chromium VI can produce teratogenic effects, probably due to the higher embryonic concentration (Danielsson et al., 1982). Danielsson et al. (1982) have studied the concentration of chromium in embryo and fetus in early and late gestational stages of mice and reported high chromium in the placenta and increased passage to the fetus, and directly affected the embryonic structures. The toxicity of chromium VI is due to its partial conversion to chromium III in the gastrointestinal tract. Coogan et al. (1991) reported higher levels of chromium VI than chromium III in tissues, which reflects the greater ability of chromium VI to cross the plasma membrane and bind to the intracellular protein in various tissues; this might explain the greater degree of toxicity of chromium VI. Embryonic and fetal levels of chromium VI in pregnant rats after exposure to chromate are reported to be ten times more toxic (Danielsson et al., 1982) than those of chromium III after exposure to corresponding doses of chromium III.

The present study indicates that sufficiently high chromium VI intake through i.p. injection during the 
period of organogenesis may cause a risk to the developing embryo and fetus. However, to elucidate his pathway of action require further studies.

\section{Acknowledgements}

The authors thank B. Azib for his excellent technical assistance. This work is supported by a grant from the Ministry of Higher Education, Scientific Research and Technology.

\section{References}

Bailey, M.M., Boohaker, J.G., Sawyer, R.D. et al. (2006). Exposure of pregnant mice to chromium picolinate results in skeletal defects in their offspring. Birth Defects Res. 77, 244-9.

Battista, M.C., Oligny, L.L., St-Louis, J. \& Brochu, M. (2002). Intrauterine growth restriction in rats is associated with hypertension and renal dysfunction in adulthood. Am. J. Physiol-Endoc. M. 283, 124-31.

Coogan, T.P., Squibb, K.S. \& Motz, J. (1991). Distribution of chromium within cells of blood. Toxicol. Appl. Pharmacol. 108, 157-66.

Danielsson, B.R.G., Hassoun, E. \& Dencker, L. (1982). Embryotoxicity of chromium: distribution in pregnant mice and effects on embryonic cells in vitro. Arch. Toxicol. 51, 233-45.

Domingo, J.L. (1994). Metal-induced developmental toxicity in mammals: a review. J. Toxicol. Environ. Health. 42, 12341.

E.P.A. (1998). Toxicological Review of Hexavalent Chromium. U.S. Environmental Protection Agency, Washington, DC.

European Commission. (2005). European Union Risk Assessment Report: Chromium Trioxide, Sodium Chromate, Sodium Dichromate, Ammonium Dichromate and Potassium Dichromate. European Commission, JRC, IHCP, ECB, Luxembourg.

Franklin, J. \& Brent, R. (1960), Interruption of uterine blood flow: a new technique for the production of congenital malformations. Comparison of the eighth, ninth, and tenth days of gestation. Surg. Forum 11, 415-6.

Gale, T.F. (1982). The embryotoxic response to maternal chromium trioxide exposure in different strains of hamsters. Environ. Res. 29, 196-203.

Garris, D. (1984). Intrauterine growth of the guinea pig fetalplacental unit throughout pregnancy: regulation by uteroplacental blood flow. Teratology 29, 93-9.

Gluckman, P.D. \& Harding, J.E. (1997). The physiology and pathophysiology of intrauterine growth retardation. Horm. Res. 48, 11-6.

Iyer, P., Gammon, D., Gee, J. \& Pfeifer, K. (1999). Characterization of maternal influence on teratogenicity: an assessment of developmental toxicity studies for the herbicide yanazine. Regul. Toxicol. Pharm. 29, 88-95.

Junaid, M., Murthy, R.C. \& Saxena, D.K. (1996a). Embryotoxicity of orally administered chromium in mice: exposure during the period of organogenesis. Toxicol. Lett. 84, 143-8.

Kanojia, R.K., Junaid, M. \& Murthy, R.C. (1996). Chromium induced teratogenicity in female rat. Toxicol. Lett. 89, 20714.

Kanojia, R.K., Junaid, M. \& Murthy, R.C. (1998). Embryo and fetotoxicity of hexavalent chromium: a long-term study. Toxicol. Lett. 95, 165-72.

Kawanishi, S., Hiraku, Y., Murata, M. \& Oikawa, S. (2002). The role of metals in site-specific DNA damage with reference to carcinogenesis. Free. Radic. Biol. Med. 32, 82232.

Lee, C.K., Lee, J.T. \& Yu, S.J. (2009). Effects of cadmium on the expression of placental lactogens and Pit-1 genes in the rat placental trophoblast cells. Mol. Cell. Endocrinol. 298, 118.

New, D. \& Coppola, P. (1977). Development of a placental blood circulation in rat embryos in vitro. J. Embryol. Exp. Morph. 37, 227-35.

Norseth, T. (1981). The carcinogenicity of chromium. Environ. Health Perspect. 40, 121-30.

Nriagu, J.O. \& Pacyna, J.M. (1988). Quantitative assessment of worldwide contamination of air, water and soils by trace metals. Nature 333, 134-9.

Pribluda, L.A. (1963). Chromium content of the long bones of rats at different stages of pregnancy. Dokl. Akad. Nauk B. SSR. 7, 206-12.

Sankaramanivel, S., Jeyapriya, R., Hemalatha, D. et al. (2006). Effect of chromium on vertebrae, femur and calvaria of adult male rats. Human Exp. Toxicol. 25, 311-8.

Schardein, J.L. (2000). Chemical-induced Birth Defects. Marcel Dekker, Inc., New York, NY.

Shmitova, L.A. (1978). The course of pregnancy in women engaged in the production of chromium and its compounds (in Russian). Sverdlovsk 19, 108-11.

Shmitova, L.A. (1980). Content of hexavalent chromium in the biological substrates of pregnant women and women in the immediate postnatal period engaged in the manufacture of chromium compounds (in Russian). Gig. Tr. Prof. Zabol. 2, 33-5.

Stohs, S.J. \& Bagchi, D. (1995). Oxidative mechanisms in the toxicity of metal ions. Free Radic Biol Med. 18, 321-36.

Tipton, I.H. (1960). The distribution of trace metals in the human body. In: M.J. Seven \& L.A. Johnson (eds), MetalBinding in Medicine, Lippincott, Philadelphia. pp. 2742.

Von Burg, R. \& Liu, D. (1993). Chromium and hexavalent chromium. J. Appl. Toxicol. 13, 225-30.

Wilbur, S., Ingerman, L., Citra, M., Osier, M. \& Wohlers, D. (2000). Toxicological Profile for Chromium. Agency for Toxic Substances and Disease Registry, Atlanta, Giorgia.

Woodall, S.M., Johnston, B.M., Breier, B.M. \& Gluckman, P.D. (1996). Chronic maternal undernutrition in the rat leads to delayed postnatal growth and elevated blood pressure of offspring. Pediatres 40, 438-43.

Xu, J., Bubley, G.L., Detrick, B., Blankenship, L.J. \& Patierno, S.R. (1996). Chromium (VI) treatment of normal human lung cells results in guanine-specific DNA polymerase, DNA-DNA cross-links and S-phase blockade of cell cycle. Carcinogenesis. 17, 1511-7. 